\title{
De cursus communicatie en samenwerking voor arts-assistenten heelkunde
}

\author{
J. Wouda, H.B.M. van de Wiel, R.P. Zwierstra, R.T. Ottow
}

\section{Samenvatting}

Sinds 1997 volgen alle derdejaars assistenten in opleiding tot chirurg een verplichte tweedaagse cursus 'Communicatie en samenwerking', waarin zij leren effectief om te gaan met lastige gesprekssituaties. In 1997 en 1998 zijn er negen cursussen verzorgd voor in totaal 99 assistenten. Het definitieve cursusprogramma werd steeds vastgesteld op geleide van ervaringen met en leerwensen over lastige gesprekssituaties van de deelnemers. Uit de evaluaties twee maanden na de cursus blijkt dat deelnemers het geleerde toepassen in hun werk. De cursus bleek goed aan te sluiten bij klinische ervaringen en leverde praktische handvatten op. Ook de plezierige, open sfeer, het onderlinge contact en de deskundige begeleiding droegen bij aan het welslagen van de cursus. De waardering varieerde over de negen cursussen. Mede op grond van opmerkingen uit de evaluatie, kwamen enkele factoren naar voren die deze verschillen in waardering verklaren. In het artikel wordt nader ingegaan op deze factoren.

\section{Inleiding}

Het belang van goede communicatie als onderdeel van de medische beroepsuitoefening wordt al vele jaren bepleit. ${ }^{1}$ Met de aandacht voor communicatievaardigheden in de opleidingen tot medisch specialist was het tot voor kort echter pover gesteld. Terwijl in de basisopleidingen en in de vervolgopleiding tot huisarts sinds de jaren zeventig aandacht wordt besteed aan het arts-patiëntcontact, constateerde Bruggemans in 1991 dat dit aspect van de beroepsuitoefening in geen van de andere vervolgopleidingen structureel voorkwam. ${ }^{2}$ De noodzaak van scholing werd echter gaandeweg ingezien. Zo kent de opleiding tot gynaecoloog sinds 1994 een landelijke, tweedaagse cursus over vrouwenhulpverlening, psychosomatiek en seksuologie, waarin veel aandacht wordt besteed aan het arts-patiëntcontact. ${ }^{3} 4$ Ook de opleiding tot chirurg kent sinds 1997 de verplichte cursus 'Communicatie en samenwerking'. Dit artikel beschrijft het ontstaan, de ervaringen en de evaluatieresultaten van de negen cursussen die in 1997 en 1998 zijn verzorgd voor in totaal
9 arts-assistenten heelkunde in hun derde opleidingsjaar.

\section{Doel en opzet van de cursus}

De cursus 'Communicatie en samenwerking' maakt deel uit van de landelijke, algemene Specialistencursus heelkunde. Aan de Specialistencursus, die sinds 1990 wordt verzorgd, nemen alle assistenten in hun derde tot en met zesde opleidingsjaar deel. De Specialistencursus richt zich vooral op de medisch-technische aspecten van de heelkunde. Incidenteel werd er ook aandacht besteed aan psychosociale aspecten en communicatie. ${ }^{5}$ De cursusleiding was van mening dat er meer aandacht aan het arts-patiëntcontact in de opleiding besteed moest worden. De Nederlandse Kankerbestrijding (KWF) bleek bereid een tweedaagse cursus over communicatie voor de assistenten mede te financieren onder de voorwaarde dat in de cursus aandacht zou worden besteed aan de oncologische zorg. Vanuit dit perspectief werden de volgende thema's in het cursusprogramma opgenomen: 
- overbrengen van teleurstellende informatie en het omgaan met de soms heftige emoties van patiënten, zoals in het slecht-nieuwsgesprek;

- signaleren en bespreken van psychische spanningen en verwerkingsproblematiek;

- het bespreken van de voor- en nadelen van een ingrijpende behandeling en hulp bieden bij besluitvorming;

- omgaan met patiënten die (medisch gezien) onredelijke of onmogelijke eisen stellen;

- samenwerking met collega's, afstemming van de zorg;

- hanteren van eigen emoties.

Bij de invulling van het programma diende daarnaast rekening te worden gehouden met het feit dat de deelnemers aan de cursus in hun basisopleiding tot arts al scholing hebben gehad in communicatievaardigheden. Deze scholing is bij enkele faculteiten zelfs vrij gedegen, waarbij ook is geoefend met moeilijke gesprekssituaties, zoals het slecht-nieuwsgesprek. 67 Bovendien hebben de deelnemers als assistent al enige jaren ervaring in de klinische praktijk opgedaan waarbij ze hun eigen 'stijl' hebben ontwikkeld in hun gesprekken met patiënten. In de cursus wordt daarom aangesloten bij deze ervaringen en wordt vermeden dat de deelnemers een nieuwe stijl van communiceren krijgen opgedrongen. Zo'n dwingende aanpak zou tot veel verzet leiden en zou zeker een nadelige uitwerking hebben op het effect van de cursus. Daarom is de cursus zodanig opgezet dat de deelnemers kunnen experimenteren met een effectievere aanpak van de communicatieproblemen die zij in hun eigen klinische praktijk ervaren.

Kern van de cursus vormen de rollenspeloefeningen met lastige gesprekssituaties. De cursus is daartoe opgebouwd uit een aantal modules rond de bovengenoemde thema's. Per module gaan een korte toelichting, (video)demonstratie en inventarisatie van ervaringen vooraf aan de rollenspeloefeningen. Na iedere oefening volgt een gestructureerde nabespreking, waarbij gebruik kan worden gemaakt van fragmenten uit de video-opname van de oefening. Bij de nabespreking worden de regels voor feedback aangehouden. ${ }^{8}$ Deze nabespreking met gerichte feedback mondt uit in adviezen en leeropdrachten voor de praktijk.

Tijdens de nabespreking wordt veel aandacht besteed aan de bezwaren en twijfels die de deelnemers uiten over de voorgestelde aanpak van het gesprek of over de uitvoerbaarheid van de gegeven richtlijnen in hun eigen werksituatie. Daarbij speelt het didactische principe practice-whatyou-preach een voorname rol. Dit principe houdt in dat de begeleiders de acceptatie en het gebruik van de communicatieve technieken bevorderen door tijdens de cursus zoveel mogelijk dezelfde technieken te gebruiken die zij de deelnemers aanbieden om beter te kunnen omgaan met hun eigen lastige gesprekssituaties. ${ }^{9}$ Deze aanpak met ruime aandacht voor weerstanden en praktische bezwaren biedt de deelnemers de noodzakelijke emotionele steun bij het zich eigen maken van de nieuwe inzichten en vaardigheden. Bovendien wordt dan duidelijk waardoor de toepassing van de vaardigheden in de praktijk wordt belemmerd. Soms geven de deelnemers elkaar bruikbare suggesties om met bepaalde belemmeringen, zoals tijdsdruk, om te gaan. Ook geven de tegenspelers in een rollenspel aan dat het spel ook voor henzelf zeer leerzaam was, omdat ze zich moesten inleven in de positie van de patiënt en daardoor aan den lijve konden ervaren wat een bepaalde gespreksaanpak van een arts betekent voor een patiënt.

Hoewel er in de cursus ruimschoots rekening wordt gehouden met bezwaren tegen 
de geboden communicatieve technieken en deze opzet zijn waarde ook heeft bewezen in andere cursussen, was er gezien het verplichte karakter van de cursus zeker weerstand te verwachten bij de deelnemers. Niet iedere assistent heelkunde heeft er behoefte aan om twee dagen in een conferentieoord bezig te zijn met onderwerpen als 'omgaan met emoties', 'moeilijke beslissingen' of 'samenwerking met collega's'. Daarom is iedere cursus grondig geëvalueerd en is het programma telkens bijgesteld om ervoor te zorgen dat het leereffect niet verloren zou gaan in de weerstand. Dit heeft in de loop der tijd geleid tot diverse aanpassingen in het cursusprogramma.

\section{Uitvoering van de cursus}

De cursus duurt vijf aaneengesloten dagdelen en vindt plaats in een conferentieoord. In 1997 zijn er vier cursussen verzorgd voor in totaal 47 assistenten en in 1998 zijn er vijf cursussen verzorgd voor in totaal 52 assistenten. De cursussen werden gespreid over het jaar gegeven.

Enkele weken voorafgaande aan een cursus ontvingen de deelnemers een inventarisatielijst. In deze lijst werd aan de deelnemers gevraagd om concrete casuïstiek te beschrijven die in de cursus aan bod zou kunnen komen. 76 van de 99 deelnemers $(77 \%)$ hebben deze inventarisatie vooraf ingevuld en opgestuurd. Tabel 1 geeft een overzicht van de gesprekssituaties die door de assistenten bij uitstek als lastig werden ervaren.

Het programma van iedere cursus werd toegesneden op de ingebrachte casuïstiek en leerwensen. Bovendien werd het programma van iedere cursus aangepast op geleide van de mondelinge en schriftelijke evaluaties van de voorafgaande cursussen.

Aan het einde van iedere cursus werd er een korte mondelinge evaluatie gehouden. Ongeveer twee maanden na afloop van een cursus kregen de deelnemers bovendien een schriftelijke evaluatie toegestuurd. In deze evaluatie werd hun gevraagd aan te geven welk leereffect zij zelf hadden bemerkt in de praktijk en hoe hun waardering was voor de cursus na enige tijd. Onderstaande resultaten zijn gebaseerd op de respons van 83 van de 99 deelnemers $(84 \%)$.

\section{Evaluatie}

Toepassing van de geleerde vaardigheden In de evaluatie werd gevraagd om een voorbeeld te noemen van de toepassing

Tabel 1. Casuïstiek van lastige gesprekssituaties.

\begin{tabular}{lr}
\hline & Aantal malen genoemd \\
\hline Slecht-nieuwsgesprek, heftige emoties van patiënt en/of familie & 6 \\
Eisende patiënten, conflicten met patiënten & 14 \\
Gesprekken met familie, b.v. over infauste prognose, euthanasie, donatie & 14 \\
Klachten van patiënten of familie & 6 \\
Agressieve patiënten, met name op de spoedeisende hulp & 5 \\
Overbrengen van teleurstellende informatie, bijvoorbeeld uitstel van & 3 \\
een operatie of een tegenvallend behandelingsresultaat & 2 \\
(Ernstig) verschil van mening met collega's of met de opleider & 2 \\
Taal- en cultuurbarrières & 72 \\
\hline Totaal & \\
\hline
\end{tabular}


van de in de cursus geleerde vaardigheden in de eigen praktijk. Tabel 2 geeft een overzicht van het aantal gesprekssituaties dat als voorbeeld werd genoemd van het gebruik van de geleerde vaardigheden. De voorbeelden zijn gerubriceerd in vijf gesprekssituaties. Ter illustratie staan in figuur 1 enkele voorbeelden van de door de deelnemers genoemde toepassingen in de praktijk.

In de evaluatie werd van een aantal lastige gesprekssituaties gevraagd hoe goed de deelnemer hiermee overweg kon vóór de cursus en hoe goed de deelnemer de situatie ná de cursus kon hanteren. De mate van bekwaamheid in het hanteren van de gesprekssituatie werd weergegeven op een tienpuntsschaal (van $0=$ volstrekt niet bedreven tot $10=$ uitermate bedreven). Tabel 3 geeft de gemiddelde bekwaamheid in het kunnen omgaan met de diverse gesprekssituaties vóór de cursus en ná de cursus. De laatste kolom toont de verandering in bekwaamheid vóór en ná de cursus. Deze veranderingen in bekwaamheid zijn alle significant $(p<0.001)$ en zijn een maat voor het door de deelnemers zelf ervaren leereffect van de cursus.

Het sterkste leereffect bemerkten de deelnemers bij het omgaan met eisende of ontevreden patiënten. Ook vonden de

Tabel 2. Voorbeelden van gesprekssituaties waarin de geleerde vaardigheden zijn gebruikt in de praktijk.

\begin{tabular}{lr}
\hline & Aantal malen genoemd \\
\hline Slecht-nieuwsgesprekken, omgaan met heftige emoties & 36 \\
Omgaan met eisende, ontevreden of agressieve patiënten & 22 \\
Toepassing van algemene inzichten over communicatie & 11 \\
Greep kunnen houden op het gespreksverloop & 10 \\
Conflicten met collega's en/of opleiders & 3 \\
Geen voorbeeld kunnen noemen & 11 \\
\hline Totaal & $94^{*}$ \\
\hline
\end{tabular}

*Enkele deelnemers noemden meer dan één voorbeeld. Het totaal aantal voorbeelden (94) is daarom hoger dan het aantal respondenten (83).

Tabel 3. Door de deelnemers gerapporteerde bekwaamheid voor een aantal gesprekssituaties (op een schaal van $0=$ volstrekt niet bedreven tot $10=$ uitermate bedreven) en leereffect (verschil tussen score voor en na de cursus).

\begin{tabular}{llll}
\hline Bekwaamheid in het hanteren van gesprekssituatie: & $\begin{array}{l}\text { vóór de } \\
\text { cursus }\end{array}$ & $\begin{array}{l}\text { ná de } \\
\text { cursus }\end{array}$ & leereffect \\
\hline Omgaan met eisende patiënten, conflicten met patiënten & 6.49 & 7.45 & .97 \\
Slecht-nieuwsgesprekken, heftige emoties hanteren & 7.01 & 7.70 & .70 \\
Bespreken van emotioneel beladen onderwerpen & 5.22 & 5.69 & .47 \\
Conflicten met collega's en/of opleiders & 6.65 & 7.10 & .45 \\
Patiënt helpen bij moeilijke beslissingen & 7.00 & 7.44 & .44 \\
Advies geven & 6.53 & 6.92 & .39 \\
Hanteren van eigen emoties & 7.16 & 7.41 & .25 \\
Alle gesprekssituaties (gemiddelde leereffect) & 6.39 & 6.95 & .56 \\
\hline
\end{tabular}


Figuur 1. Enkele voorbeelden van het gebruik van de geleerde inzichten en vaardigheden.

\section{Slecht-nieuwsgesprekken}

- Ik had de neiging om te veel uit te leggen. Nu doe ik dat niet meer en de boodschap komt beter over.

- Patiënt overleden na tentamen suicidii. Slecht nieuws vertellen aan familie.

- Slecht-nieuwsgesprek bij patiënt in terminale stadium bij gemetastaseerd coloncarcinoom.

- In emotionele gesprekken de patiënt niet overladen met informatie.

Eisende, ontevreden of agressieve patiënten

- Minder snel in de rede vallen van ontevreden patiënt die zijn hart wil luchten.

- Bij patiënt met diverticulitis die zeer agressief was in verband met onvoldoende effect van behandeling. Door begrip te tonen kwam zijn angst voor coloncarcinoom naar boven.

- Recent een conflict met patiënt met oorpijn. Ik had hiervoor geen verklaring. Patiënt wilde per se een KNO-arts zien (op vrijdagavond). Conflict dreigde te escaleren, maar door goed luisteren en bemiddelen werd er een oplossing gevonden.

- Door actief luisteren de emoties van een patiënt met een (onterechte) klacht bedaard. Daardoor geschil eerder opgelost.

- Boze familie met verwijten naar dokter en verpleging. Gesprek naar ander tijdstip en andere locatie verschoven. Daarbij duidelijk ingegaan op oorzaak van de emoties bij de familie.

\section{Greep houden op gespreksverloop}

- In een stroef lopend gesprek even terugkijken wat er gebeurt en waarover het gaat met daarna een samenvatting werkt zeer verhelderend. Echter de tijdsdruk speelt een grote rol en daardoor maak ik toch nog fouten in gesprekken.

- In gesprek met een 'lastige' patiënt ben ik buiten het gesprek gestapt en heb ik de situatie benoemd. Daarna konden we weer naar elkaar luisteren.

\section{Toepassing van algemene inzichten}

- De cursus was vooral een steun in de rug. Voel me nu een stuk zekerder over de aanpak die ik al hanteerde.

- Loop momenteel IC-stage. Veel gesprekken met familie onder andere over iatrogeen letsel. Openheid wordt door familie als positief ervaren.

- Beter leren luisteren naar wat niet wordt uitgesproken.

Conflicten met collega's en opleiders

- Zakelijker aanpak van onderhandelingen over dienstroosters: eerst eens worden en dan pas afspraken maken.

- In de onderhandelingen met het ziekenhuismanagement over onze 46-urige werkweek.

deelnemers dat hun vaardigheden in het brengen van slecht nieuws en het bespreken van emotioneel beladen onderwerpen verbeterd was. Minder effect werd er gerapporteerd wat betreft de vaardigheden rond advies en begeleiding. Met de eigen emoties kon men nauwelijks beter omgaan, hoewel daaraan in de cursus wel degelijk aandacht werd besteed.

Over alle gesprekssituaties gemiddeld schatte men de eigen bekwaamheid vóór de cursus in op 6.39. Ná de cursus werd deze algemene bekwaamheid ingeschat op 6.95. Het gemiddelde verschil in 
bekwaamheid vóór en ná de cursus bedroeg derhalve 0.56. Dit verschil geeft het gemiddelde leereffect van de cursus weer zoals dat door de deelnemers zelf werd ervaren.

\section{Waardering voor de cursus}

De gemiddelde waardering voor de negen cursussen, uitgedrukt in een rapportcijfer $(0=$ volstrekt waardeloos; $10=$ perfecte cursus), was 7.4. Dit oordeel wisselde echter per cursus.

Figuur 2 geeft de gemiddelde waardering weer per cursus. De grafiek laat zien dat de waardering voor de eerste en tweede cursus vrij goed was. Bij de derde cursus zakt de waardering om bij de vierde weer op het oude niveau terug te keren. Daarna is er weer een teruggang bij de vijfde cursus gevolgd door een langzaam stijgende lijn voor de zesde tot en met achtste cursus met een kleine terugval bij de negende cursus. Figuur 2 laat tevens de verschillen zien tussen de cursussen in het door de deelnemers zelf ervaren gemiddelde leereffect. Het leereffect van de afzonderlijke cursussen volgt een vergelijkbaar patroon als de waardering.

In de evaluatie werd gevraagd de positieve en minder positieve aspecten van de cursus te vermelden. Uit de positieve opmerkingen sprak vooral de waardering voor:

- het praktische karakter van de cursus;

- veel ruimte voor eigen ervaringen;

- bruikbare inzichten en vaardigheden;

- de mogelijkheid om zelf te oefenen;

- een open, veilige en plezierige sfeer;

- uitwisselen van ervaringen met collega's uit andere ziekenhuizen;

- de goede begeleiding.

Figuur 2. Gemiddelde waardering en leereffect van de negen cursussen.

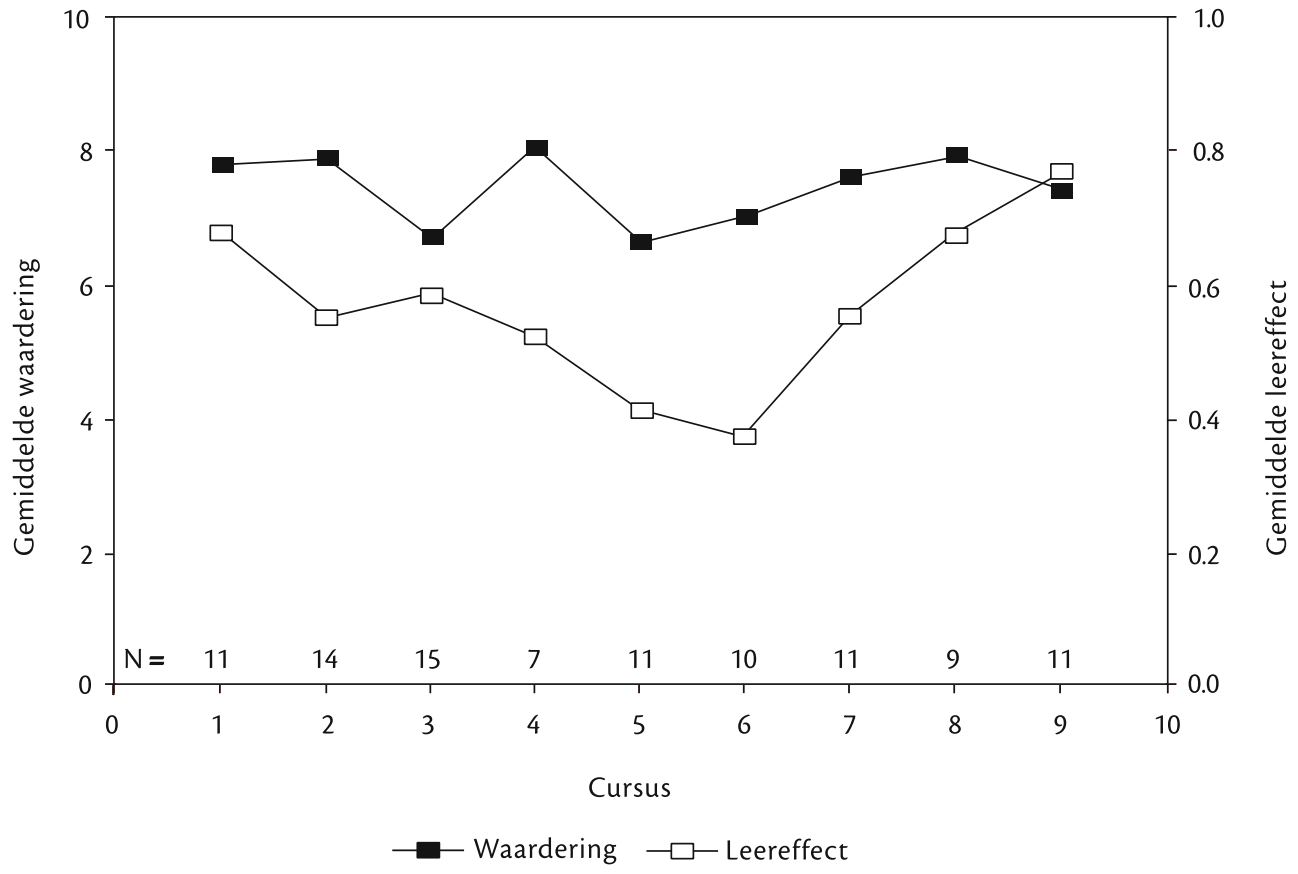


Minder positief was men over de aspecten:

- een te intensief programma, met name op de eerste dag;

- te lange cursus;

- te weinig afwisseling;

- overlap met andere cursussen;

- te weinig gelegenheid om te oefenen met simulatiepatiënten;

- voor- en nabespreken van de rollenspellen kost te veel tijd;

- te weinig aandacht voor het probleem 'tijdgebrek' in de (poli)klinische praktijk;

- te weinig aandacht voor de positie van de assistent en voor conflicten met opleiders en/of ziekenhuisdirectie.

Het aantal positieve opmerkingen over de cursussen volgt eenzelfde patroon als de waardering. De negatieve opmerkingen volgen echter een ander patroon. In de eerste plaats was het opvallend dat er over de eerste cursus relatief veel negatieve opmerkingen werden gemaakt, terwijl deze cursus toch goed werd gewaardeerd. De negatieve opmerkingen over de eerste cursus betroffen vooral de hoge intensiteit van de cursus en het avondprogramma op de eerste dag over palliatieve zorg.

In de tweede en derde cursus is het programma aangepast. In de tweede cursus leidde dat tot iets minder negatieve opmerkingen, maar geen hogere waardering. De waardering voor de derde cursus was zelfs beduidend lager. Er bleek een ander probleem te spelen, namelijk de omvang van de groep. De groepen van veertien en vijftien deelnemers bleken te groot om iedereen voldoende aan bod te laten komen. De negatieve opmerkingen gingen grotendeels hierover. Daarom werd besloten om in het vervolg niet meer dan twaalf deelnemers per cursus toe te laten.

Voor de vierde cursus is het programma weer wat aangepast. Meer dan voorheen is in deze cursus gebruik gemaakt van een simulatiepatiënt en is het bekijken van de video-opnames beperkt. Deze ingrepen gekoppeld aan het kleine aantal (zeven) deelnemers leverde een cursus op die uitstekend liep, zoals blijkt uit de waardering (8) en de daling van het aantal negatieve opmerkingen.

De vijfde tot en met negende cursus vonden plaats in 1998. Om de theoretische uitleg in de cursus te beperken en meer tijd te krijgen voor de oefeningen in kleine groepen, kregen de deelnemers dit jaar het boekje 'Wie is de baas' vooraf toegestuurd met daarin de theoretische achtergronden over lastige gesprekken. ${ }^{10}$ Voorheen kregen de deelnemers dit boekje na de cursus uitgereikt. Deze als stimulans bedoelde actie had echter niet het gewenste effect. Hoewel het programma vrijwel identiek was aan de vorige cursus en alleen het aantal deelnemers wat groter was, daalde de waardering en nam het aantal negatieve opmerkingen weer toe. Het bleek dat het boekje zo goed was gelezen dat de deelnemers dachten direct aan de gang te kunnen gaan met de moeilijkste gesprekken. Men vond de cursus nu traag verlopen en had meer 'spektakel' verwacht.

Op grond van deze ervaring is het programma weer wat anders opgebouwd. Wetende dat de cursisten de theorie hebben gelezen, maar de vaardigheden zeker nog niet beheersen, had de cursusleiding op de eerste cursusdag nu vooral de lastige gesprekken op het programma gezet waarbij de eigen oplopende emoties van de arts een rol spelen. Het doel van de oefeningen hiermee is niet zozeer het aanleren van 'gevorderde' vaardigheden, maar vooral het leren hanteren van de meer basale gespreksvaardigheden bij oplopende eigen emoties. Ook in het avondprogramma stonden de eigen emoties en de onderlinge verstandhouding meer centraal. 
Deze aanpak bleek redelijk succesvol. De deelnemers aan de zesde cursus vonden het programma vooral vermoeiend en vol, maar niet meer saai. Bij de zevende cursus is het programma van de eerste dag wat compacter gemaakt en zijn er meer ontspannende elementen ingebouwd. De waardering voor deze cursus en de volgende cursus kwam daardoor op hetzelfde niveau uit als voor de eerste cursussen. De waardering voor de laatste cursus toont echter weer enige terugval. Een mogelijke verklaring hiervoor is dat acht van de elf deelnemers aan deze cursus reeds eerder een 'gevorderde' cursus over communicatievaardigheden hadden gevolgd. Voor hen bood de cursus blijkbaar te weinig nieuws. Dit blijkt ook uit de antwoorden op de vraag of men een vervolg op de cursus op prijs stelt. $58 \%$ van de respondenten van de eerste acht cursussen stelt zo'n vervolg in de vorm van een korte herhalingsoefening of extra verdieping op prijs. Dit percentage is vrij constant voor deze cursussen. Veel respondenten gaven daarbij aan dat in de hectiek van het dagelijks werk de in de cursus geleerde vaardigheden snel wegzakken en dat een vervolg in een latere fase van de opleiding nodig is. Bij de laatste (negende) cursus waren er maar twee van de negen respondenten geïnteresseerd in een vervolg.

\section{Conclusies en aanbevelingen}

Uit de evaluatie na ruim twee maanden blijkt dat de cursus effect heeft op de contactuele vaardigheden van de deelnemers. De cursus sluit goed aan bij de eigen klinische ervaringen en levert voldoende praktische handvatten op. De plezierige, open sfeer, het onderlinge contact en de deskundige begeleiding bieden de voorwaarden om in de cursus vruchtbaar te kunnen oefenen met lastige gesprekssituaties. De cursus 'Communicatie en samenwerking' voor derdejaars arts-assistenten heelkunde vol- doet ons inziens daarmee aan de verwachtingen. Uit de twee jaar ervaring met de cursus blijkt dat een aantal randvoorwaarden van belang is voor het welslagen van de cursus en het bereiken van het gewenste leereffect:

- De cursus moest minder intensief worden. Vijf dagdelen bezig zijn met communicatie is voor een chirurg in opleiding te veel van het goede.

- Het aantal deelnemers dient beperkt te blijven tot maximaal twaalf.

- Tijdens de cursus moeten de deelnemers niet alleen onderling oefenen, maar ook met simulatiepatiënten om het realiteitsgehalte van de oefeningen te waarborgen en het leereffect te vergroten.

- De cursus moet door zijn inhoud en opzet uitdagend blijven, ook al hebben de deelnemers de theoretische achtergronden bestudeerd en soms ook al vergelijkbare cursussen gevolgd.

- De cursus moet voldoende afwisseling bieden, niet alleen wat betreft de thema's die aan bod komen, maar ook wat betreft de gehanteerde werkwijzen.

- Meer dan de helft van de deelnemers heeft behoefte aan een vervolg op de cursus later in de opleiding om het geleerde op te frissen. Zo'n herhaling dient echter voldoende nieuwe elementen te bevatten om nog aantrekkelijk te zijn voor de inmiddels ervaren deelnemers.

\section{Literatuur}

1. Ong LML, Haes JCJM de, Hoos AM, Lammes FB. Doctor-patient communication: review of the literature. Soc Science Med 1995;40:903-18.

2. Bruggemans E. De communicatie tussen arts en patient. Den Haag: Nederlandse Hartsstichting; 1991.

3. Wouda J, Wiel HBM van de, Weijmar Schulz WCM. Training communicatieve vaardigheden voor gynaecologen - het waarom en het hoe. Nederlands Tijdschrift voor Obstetrie \& Gynaecologie 1992;105:130-6.

4. Klein Tank M. Training leert gynaecologen geslachtsdelen bij de naam te noemen. Tijdschrift Gezondheidsvoorlichting 1997;14(11):18-20. 
5. Zwierstra RP, Scherpbier AJJA, Schilfgaarde R van. De specialistencursus heelkunde. Bulletin Medisch Onderwijs 1993;12:3-9.

6. Wouda J, Wiel HBM van de. Communicatieve vaardigheden: een diagnose en een advies. Bulletin Medisch Onderwijs 1992;11:116-8.

7. Batelaan MA. Inventarisatie onderwijs communicatieve vaardigheden faculteiten geneeskunde. Amsterdam: Vakgroep Medische Psychologie, Vrije Universiteit; 1995.

8. Wouda J, Wiel HBM van de, Vliet KP van. Medische communicatie: gespreksvaardigheden voor de arts. Utrecht: Elsevier; 1997.

9. Wouda J, Wiel HBM van de. Cursus communicatie voor medisch specialisten. In: Smal JA, Cate ThJ ten, Denekens J, Dikkers JH, Remmen R, Smal JA et al. redactie. Gezond Onderwijs-6. Houten/Diegem: Bohn Stafleu Van Loghum; 1997. p. 293-8.

10. Wiel HBM van de, Wouda J, Weijmar Schultz WCM. Wie is de baas: lastige gesprekken in de medische praktijk. Groningen: Ahmas; 1996.

\section{De auteurs:}

Drs. J. Wouda, docenttrainer Onderwijsinstituut, Faculteit der Medische Wetenschappen, Groningen. Prof. dr. H.B.M. van de Wiel, medisch psycholoog, Dienst Medische Psychologie, Academisch Ziekenhuis Groningen.

Prof. dr. R.P. Zwierstra, directeur Onderwijsinstituut, Faculteit der Medische Wetenschappen, Groningen. Dr. R.T. Ottow, chirurg, Afdeling Heelkunde, Groene Hart Ziekenhuis, Gouda.

Correspondentieadres:

J. Wouda, Onderwijsinstituut, Faculteit der Medische Wetenschappen, A. Deusinglaan 1, 9713 AV

Groningen,050-3636173, j.c.wouda@med.rug.nl.

\section{Summary}

Since 1997 the two-day course Communication and Cooperation has been compulsory for all surgical residents in the Netherlands. The course teaches residents how to deal effectively with problems in communication with patients and others. In 1997 and 1998 nine courses were attended by a total of 99 residents. The course programmes were based on participants' experiences and learning objectives and on the results of written evaluations of previous courses. The evaluation results show the relevance of the course to clinical practice. Residents report that they actually use what they have learned. The positive and open atmosphere, the mutual exchange of experiences and the expertise of the course facilitators also contributes to the success of the course. The appreciation of the course varied across the nine courses. From the evaluations some factors emerged that explained these differences. These factors are discussed in the article. (Wouda J, Wiel HBM van de, Zwierstra RP, Ottow RT. The Communication and Cooperation Course for surgical residents. Dutch Journal of Medical Education 2000;19(4):142-50) 